\title{
Randomized controlled clinical trial comparing the efficacy and tolerability of aripiprazole and sodium valproate in the treatment of Tourette syndrome
}

\author{
Deshuang Tao ${ }^{1,5}$, Tangwu Zhong ${ }^{1}$, Shuxia Ma ${ }^{1}$, Jialin $\mathrm{Li}^{1}$ and Xiaojie $\mathrm{Li}^{1,2,3,4^{*}}$
}

\begin{abstract}
Objective: This study compared the efficacy and tolerability of sodium valproate and aripiprazole in the treatment of Tourette syndrome (TS).

Method: 24 children and adolescents with a diagnosis of TS from the Jiamusi Central Hospital between January 2014 and August 2017 were randomly divided into sodium valproate group and aripiprazole group according to the order of clinic visits and treated for 10 days. Tic severity was rated using the Yale Global Tic Severity Scale (YGTSS) and the Clinical Global Impressions Scale for tics (CGI-Tics) and the adverse reactions were valued using the Treatment Emergent Symptom Scale (TESS) at baseline and at each follow-up visit.
\end{abstract}

Results: The TTS score in the YGTSS scale decreased over time in both groups while the aripiprazole group was significantly higher on the 5 th day $(p<0.05)$ and 10th day $(p<0.05)$ than the sodium valproate group. There was no significant difference in TESS score between the two groups.

Conclusions: The study indicates that the patients treated with sodium valproate injection have a faster onset time than the patients treated with oral aripiprazole in controlling tics.

Keywords: Aripiprazole, Sodium valproate, Treating, Tourette syndrome, Clinical trial

\section{Introduction}

Tourette syndrome (TS), also known as Gilles de la Tourette syndrome, is a childhood-onset condition characterized by chronic motor and vocal tics. It has been estimated that about $1 \%$ of school-age children have TS [1]. But unfortunately the exact mechanisms have not been elucidated. Family studies [2] show that the incidence of TS in first-degree relatives of TS patients is 10-100 times higher than that of the general population. Probably the most accepted current hypothesis regarding the underlying pathophysiology and pathological anatomy of TS is that there is an impairment of cortical inhibition of motor programs that are spontaneously

\footnotetext{
*Correspondence: dazhumama@yeah.net

${ }^{3}$ Rehab Center for Child CP, Jiamusi, Heilongjiang, China

Full list of author information is available at the end of the article
}

generated in the basal ganglia and expressed. Available evidence also supports involvement of cortico-striatalthalamo-cortical (CSTC) circuits and their interconnecting brain regions in the pathophysiology of tics [3]. Several neurotransmitters, including dopamine, GABA and glutamate, play an important role within CSTC circuitry and have been proposed to have roles in both habitual behavior formation and in the pathophysiology of tics [4-8]. Multiple neurotransmitter abnormalities and their signaling may also lead to dysfunction of the CSTC neural network and subsequent clinical manifestations of TS. The pathogenesis of TS is also associated with excessive neurotrophic effects and pro-toxic effects of excitatory amino acids (EAA) in the brain [9]. Astrocyte-specific induction of knockout of EAAT2 in mice has been shown to result in pathological repetitive selfmodification and twitch-like head shaking associated

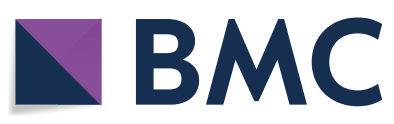

(c) The Author(s) 2019. This article is distributed under the terms of the Creative Commons Attribution 4.0 International License (http://creativecommons.org/licenses/by/4.0/), which permits unrestricted use, distribution, and reproduction in any medium, provided you give appropriate credit to the original author(s) and the source, provide a link to the Creative Commons license, and indicate if changes were made. The Creative Commons Public Domain Dedication waiver (http://creativecommons.org/ publicdomain/zero/1.0/) applies to the data made available in this article, unless otherwise stated. 
with glutamate hyperexcitability [10]. Short-term sodium valproate treatment augmented EAAT1 translocation to the cell membrane, whereas prolonged or chronic sodium valproate treatment resulted in an upregulation of EAAT1 mRNA and protein levels, as well as glutamate transport and production of glutamine. The treatment of TS involves appropriate education and support. Tics can be treated with habit reversal cognitive behavioral therapy [11], pharmacotherapy [12], local intramuscular injections of botulinum toxin [13] and some severe, refractory cases have responded to deep brain stimulation surgery (DBS) [14]. However, the cost of treatment and the risk of surgery still restrict its widespread development. How to control tics quickly for people whose condition seriously affects the daily life is very important.

The atypical antipsychotic aripiprazole is a dopamine D2- and serotonin 5-hydroxytryptamine (5-HT)1A receptor partial agonist and 5-HT2A receptor antagonist [15] that is approved by the United States and South Korea for the treatment of tic disorder. Generally, pediatric patients whose oral aripiprazole at doses of 5-, 10-, $15-$, or $30 \mathrm{mg} /$ day and adjusted according to the efficacy and side effects. Sodium valproate controls tics by regulating central GABA system function including enhancing gamma-aminobutyric acid (GABA) synthesis and inhibiting GABA degradation and directly stimulating GABA-A receptors to increase GABA levels and up-regulate excitatory amino acid transporter (EAAT) 1 mRNA and protein levels and sodium valproate injection is the first line of medication to control the status of epilepsy. In order to understand the efficacy of sodium valproate injection in controlling the patients with a diagnosis of TS, our department selected 24 patients with acute severe tic and compared with oral aripiprazole.

\section{Participant characteristics}

Eligible patients were aged 6-16 years (20 males, 4 females; mean \pm SD age $=9.9 \pm 3.3$ years) with a diagnosis of TS (Diagnostic and Statistical Manual of Mental Disorders, Fourth Edition, Text Revision [DSM-IV-TR]) (American Psychiatric Association 2000), confirmed by the Kiddie Schedule for Affective Disorders and Schizophrenia-Present and Lifetime Version; with a Yale Global Tic Severity Scale Total Tic Score (YGTSSTTS) $\geq 30$ at screening were recruited at Jiamusi Central Hospital from January 2014 to August 2017. Before determining eligibility, we obtained informed consent from both the study subject and the child's primary caregiver. The study protocol was approved by our local Institutional Review Board. Each patient was subsequently examined by a board-certified child psychiatrist. However, patients with any of the following characteristics were excluded from the study: included current psychotic symptoms. Subjects with an IQ $\leq 70$ on the Wechsler Intelligence Scale for Children-Revised (WISC$\mathrm{R})$, as were patients with previous or current seizure episodes, electroencephalogram (EEG) abnormalities, and those who had used aripiprazole and sodium valproate previously, people who were hypersensitive to sodium valproate or aripiprazole were also excluded, and patients had no significant abnormalities in laboratory results, including serum chemistries, hematology, urinalysis.

\section{Study design}

All subjects were evaluated at baseline by routine laboratory tests, electrocardiogram (ECG), resting pulse rate and blood pressure while sitting, height and weight measurement, medical history, and physical and neurological examinations. The patients were assigned by a randomization within our hospital. Briefly, after the patients passed the inclusion/exclusion criteria and gave consent for the study, they were numbered serially at our hospital by one "special doctor" according to the order of visits and then we use the random number table for grouping. The odd number selects sodium valproate, the even number chooses aripiprazole. The "special doctor" was not involved in the grouping and treatment. Patients in the aripiprazole group started at a dose of $2.5 \mathrm{mg} /$ day if weight $<50 \mathrm{~kg}$, which was increased to $5.0 \mathrm{mg} /$ day 5 days later; Patients started at a dose of $5 \mathrm{mg} /$ day if weight $\geq 50 \mathrm{~kg}$, which was increased to $10.0 \mathrm{mg} /$ day 5 days later in the aripiprazole group. The sodium valproate was dissolved in $20 \mathrm{ml}$ saline $(0.9 \% \mathrm{NaCl})$ at a dose of $15 \mathrm{mg} / \mathrm{kg}$ within $5 \mathrm{~min}$ and given intravenously once every $12 \mathrm{~h}$. Patients were assessed every 5 days.

\section{Measurements}

Symptom severity was assessed by the principal investigator. The primary efficacy endpoint was the YGTSS mean change (including YGTSS-motor scores, YGTSS-phonic scores, YGTSS-total scores, YGTSS-impairment scores) from pretreatment baseline to 10 days. The YGTSS [1620] is a semi-structured clinical interview designed to assess current tic severity; this scale yields three summary scores; total motor (0-25), total phonic (0-25), and total tic (sum of motor and phonic) scores. The YGTSS also contains an impairment scale (0-50), which evaluates the global level of functional impairment arising from tics. Because this study was designed to compare not only efficacy in reducing tic symptoms, but also the global level of functional impairment, so the primary outcome measure contains YGTSS-motor scores, YGTSS-phonic scores, YGTSS-total tic scores, and YGTSS-impairment scores. The YGTSS was administered to each subject at each visit. Secondary outcome measures included the Clinical Global Impressions-Improvement scale [21] (CGI-I), 
Scores of 1 (very much improved) or 2 (much improved) in the CGI-I were regarded as positive responses. Adverse effects associated with these drugs were assessed using the Treatment Emergent Symptom Scale (TESS) [22], which included the most commonly encountered side effects of aripiprazole and sodium valproate, as well as general questions on health issues, current illnesses or injuries, and concomitant medical treatments. At the study endpoint, physical and neurological examinations, laboratory tests, and ECG assessments were repeated. All tests were admitted by a single psychiatrist, who was blinded to dose changes and the drug of choice.

\section{Statistical analyses}

Analyses were performed using SPSS 24. The demographic and clinical characteristics of samples are described in terms of means, standard deviations, range, and proportions as needed. Independent sample $t$ test and repeated measures analysis of variance was applied when the measurement data would follow a normal distribution or nonparametric statistics was applied where the measurement data are not normal distribution.
Count data using $X^{2}$ test. This study was an open-label design, with each subject contributing baseline and post-treatment measures. Significance is judged at level $p=0.05$, two-sided (Fig. 1).

\section{Results}

\section{Participant characteristics}

Our hospital diagnosed and treated 723 tic disorder patients from 2014 to 2017, of which 248 patients had simple tic symptoms and the YGTSS scores ranged from 4 to 6 , so they had no drug treatment but were given health guidance. 438 patients scored less than 25 , the patient chose oral small doses of aripiprazole or clonidine transdermal patches or other Chinese medicine treatment. 37 people met the criteria for inclusion in this experiment, and 24 (64.9\%) agreed to participate in the treatment. Of the 24 children and adolescents with Tourette syndrome, 12 were prescribed aripiprazole and 12 were prescribed sodium valproate. The age range is 6-16 years and the average age is 9.96 . The mean duration of illness was $2.77 \pm 0.92$ years. The gender ratio, total IQ, comorbid conditions, duration of illness, and

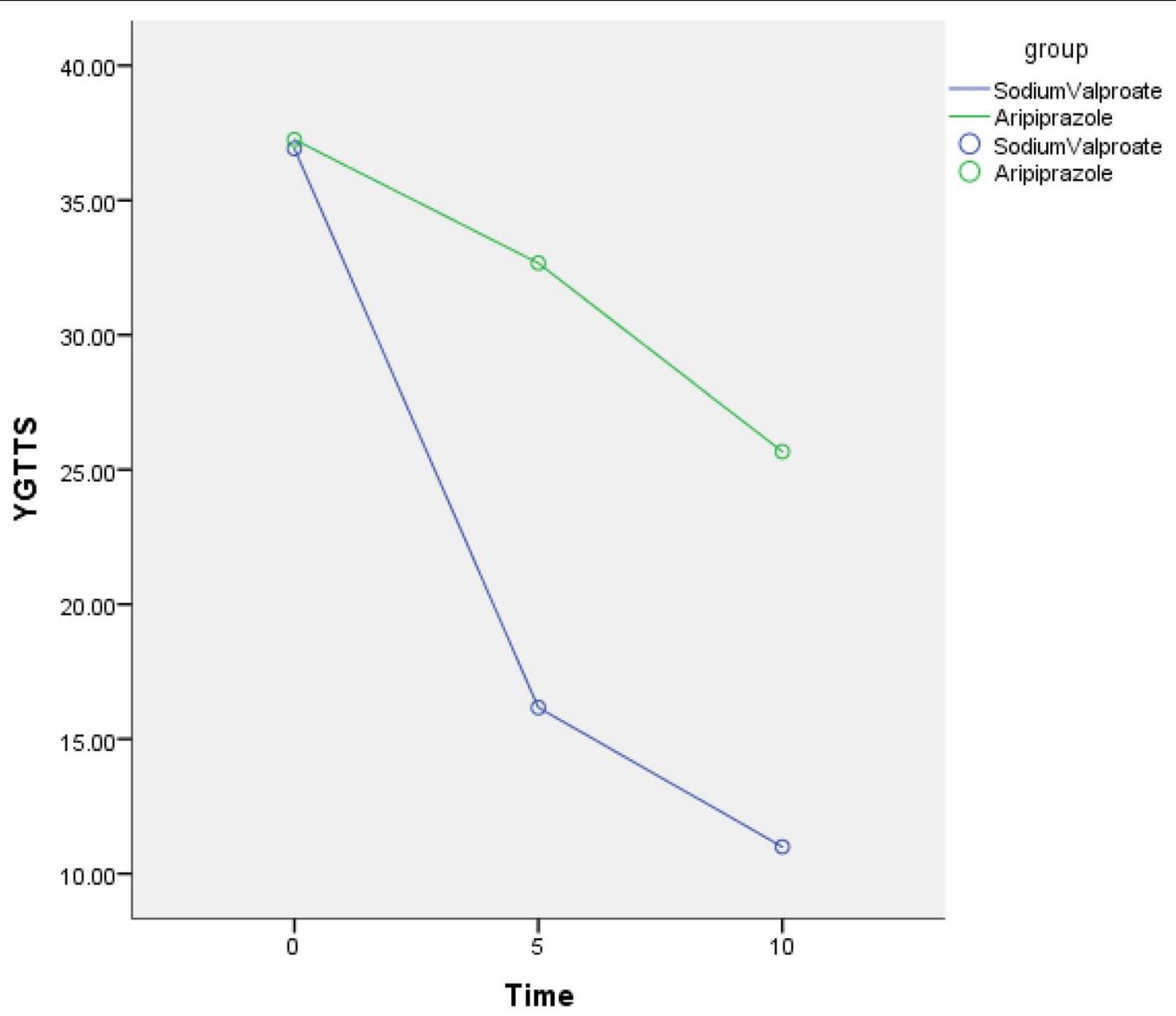

Fig. 1 The mean YGTSS Total Tic scores from baseline to endpoint 
study medications did not differ between the two groups $(p>0.05)$. Twelve participants $(50 \%)$ had other comorbid psychiatric disorders, the most common being anxiety disorder (20.83\%) (Table 1).

\section{Efficacy of aripiprazole and sodium valproate: Yale Global Tic Severity Scale}

At baseline there were no significant between-group differences in tic scores, but at each follow-up visit, tic scores including total tic scores (YT) [Fig. 1], total motor scores (YM) [Fig. 4] total phonic scores (YP) [Fig. 3] and impairment scale scores (YI) [Fig. 2] decreased over time in both groups indicating that these two drugs were efficacious in reducing tic symptoms (Table 2). Patients with severe TS had mean $( \pm \mathrm{SD})$ pretreatment (baseline) YGTSS Global Severity score $(33.33 \pm 4.92)$ declined significantly to end point $(2.50 \pm 4.52 ; p<0.001)$ while YGTSS Total Tic scores declined significantly from baseline $(36.92 \pm 5.16)$ to end point $(11.00 \pm 3.36 ; p<0.001))$ in the sodium valproate group. Patients had mean $( \pm \mathrm{SD})$ pretreatment (baseline) YGTSS Global Severity score $(34.17 \pm 5.15)$ declined significantly to end point $(20.00 \pm 4.26 ; p<0.001)$ while YGTSS Total Tic scores also declined significantly from baseline $(37.25 \pm 4.77)$ to end point $(25.67 \pm 4.62 ; p<0.001)$ in the aripiprazole group. This reduction was particularly marked at the first follow-up visit (5th day) in both groups and was sustained throughout the study period. At the first followup visit there has significant differences between-group with YGTSS Total Tic scores and YGTSS Global Severity score. There were significant between-group effects or interactions (Table 2).

\section{Efficacy of aripiprazole and sodium valproate: clinical global impression}

Ten (83.33\%) subjects achieved CGI-Tic Improvement scores of 1 ("very much improved") or 2 ("much improved") in the sodium valproate group while seven (58.33\%) subjects achieved CGI-Tic Improvement scores of 2 ("much improved") in the aripiprazole group at the first follow-up visit so there was a statistically significant difference between the sodium valproate group and the aripiprazole group $(Z=-2.705, p=0.008)$. Although the tics score decreased during the treatment in both groups, the patient's self-evaluation or psychological improvement of the disease in the sodium valproate group was

Table 1 Demographic and clinical characteristics of the 24 children and adolescents with TS

\begin{tabular}{|c|c|c|c|c|}
\hline & Sodium valproate $(n=12)$ & Aripiprazole $(n=12)$ & $x^{2} / t / Z$ & $p$ \\
\hline Sex & & & 0.000 & $>0.999$ \\
\hline Male & 10 & 10 & & \\
\hline Female & 2 & 2 & & \\
\hline Age & $9.75 \pm 3.42$ & $10.17 \pm 3.43$ & 0.298 & 0.768 \\
\hline Weight & $34.75 \pm 9.88$ & $34.67 \pm 7.79$ & 0.023 & 0.982 \\
\hline Duration of tic disorders & $3.00(2.00,3.38)$ & $2.75(2.00,3.78)$ & 0.060 & 0.977 \\
\hline IQ & $96.08 \pm 6.83$ & $97.17 \pm 7.93$ & 0.359 & 0.723 \\
\hline \multicolumn{5}{|l|}{ Comorbidities, $n \%$} \\
\hline ADHD & $3,25 \%$ & $1,8.33 \%$ & & \\
\hline ODD & $1,8.33 \%$ & $1,8.33 \%$ & & \\
\hline OCD & $1,8.33 \%$ & 0 & & \\
\hline Emotional disorder & $216.67 \%$ & $2,16.67 \%$ & & \\
\hline Anxiety disorder & $5,41.67 \%$ & $2,16.67 \%$ & & \\
\hline Depressive disorder & 0 & $1,8.33 \%$ & & \\
\hline
\end{tabular}

Table 2 Efficacy of sodium valproate and aripiprazole in the treatment of TS

\begin{tabular}{|c|c|c|c|c|c|c|c|c|c|c|c|c|}
\hline & \multicolumn{3}{|c|}{ Sodium valproate } & \multicolumn{3}{|l|}{ Aripiprazole } & \multicolumn{2}{|l|}{ Group } & \multicolumn{2}{|l|}{ Time } & \multicolumn{2}{|c|}{ Group $\times$ time } \\
\hline & Baseline & 5 days & 10 days & Baseline & 5 days & 10 days & $F$ & $p$ & $F$ & $p$ & $F$ & $p$ \\
\hline YM & $19.08(2.23)$ & $9.83(1.53)$ & $6.33(1.23)$ & $19.08(2.19)$ & $16.83(1.99)$ & $13.17(2.48)$ & 64.907 & $<0.001$ & 177.651 & $<0.001$ & 31.961 & $<0.001$ \\
\hline YV & $17.83(3.33)$ & $6.33(2.54)$ & $4.67(3.28)$ & $18.17(2.76)$ & $15.83(3.04)$ & $12.50(2.43)$ & 95.256 & $<0.001$ & 23.863 & $<0.001$ & 46.152 & $<0.001$ \\
\hline YF & $33.33(4.92)$ & $11.67(3.89)$ & $2.50(4.52)$ & $34.17(5.15)$ & $25.83(5.15)$ & $20.00(4.26)$ & 198.000 & $<0.001$ & 62.663 & $<0.001$ & 29.333 & $<0.001$ \\
\hline YT & $36.92(5.16)$ & $16.17(3.10)$ & $11.00(3.36)$ & $37.25(4.77)$ & $32.67(4.98)$ & $25.67(4.62)$ & 164.455 & $<0.001$ & 63.035 & $<0.001$ & 35.209 & $<0.001$ \\
\hline
\end{tabular}


Table 3 The rate of adverse effects by the groups

\begin{tabular}{ccllrl}
\hline & Time (days) & Sodium valproate $(\mathbf{n = 1 2})$ & Aripiprazole $(\mathbf{n}=12)$ & $\boldsymbol{Z}$ & $\boldsymbol{p}$ \\
\hline CGI-I & 5 & $1.00(1.00,2.00)$ & $2.00(2.00,3.00)$ & -2.705 & -3.104 \\
& 10 & $1.00(1.00,1.00)$ & $2.00(2.00,2.00)$ & -0.173 \\
TESS & 5 & $0.00(0.00,1.00)$ & $0.00(0.00,1.00)$ & -0.004 \\
& 10 & $1.00(0.25,1.75)$ & $1.00(0.25,1.00)$ & 0.887 \\
\hline
\end{tabular}

better than in the aripiprazole group. The CGI-I scores of both groups decreased over time $(Z=-2.705, p=0.008)$ without significant between-group effects or interaction effects (Table 3).

\section{The Treatment Emergent Symptom Scale}

Most common adverse effects were mild which included nausea (4 patients), drowsiness (4 patients), decreased appetite ( 1 patient), and sensitivity ( 1 patient) in the sodium valproate group emerged at the beginning while getting better with time.
Adverse effects in the aripiprazole group emerged when the dose was increased in an attempt to target symptoms that did not respond to lower dosage included hypersomnia (4 patient), xerostomia ( 2 patient), decreased appetite (1 patient), decreased sleep (1 patient), and tremor (1 patient). At the two follow-up visits, there was no significant difference in adverse events between groups (Table 3).

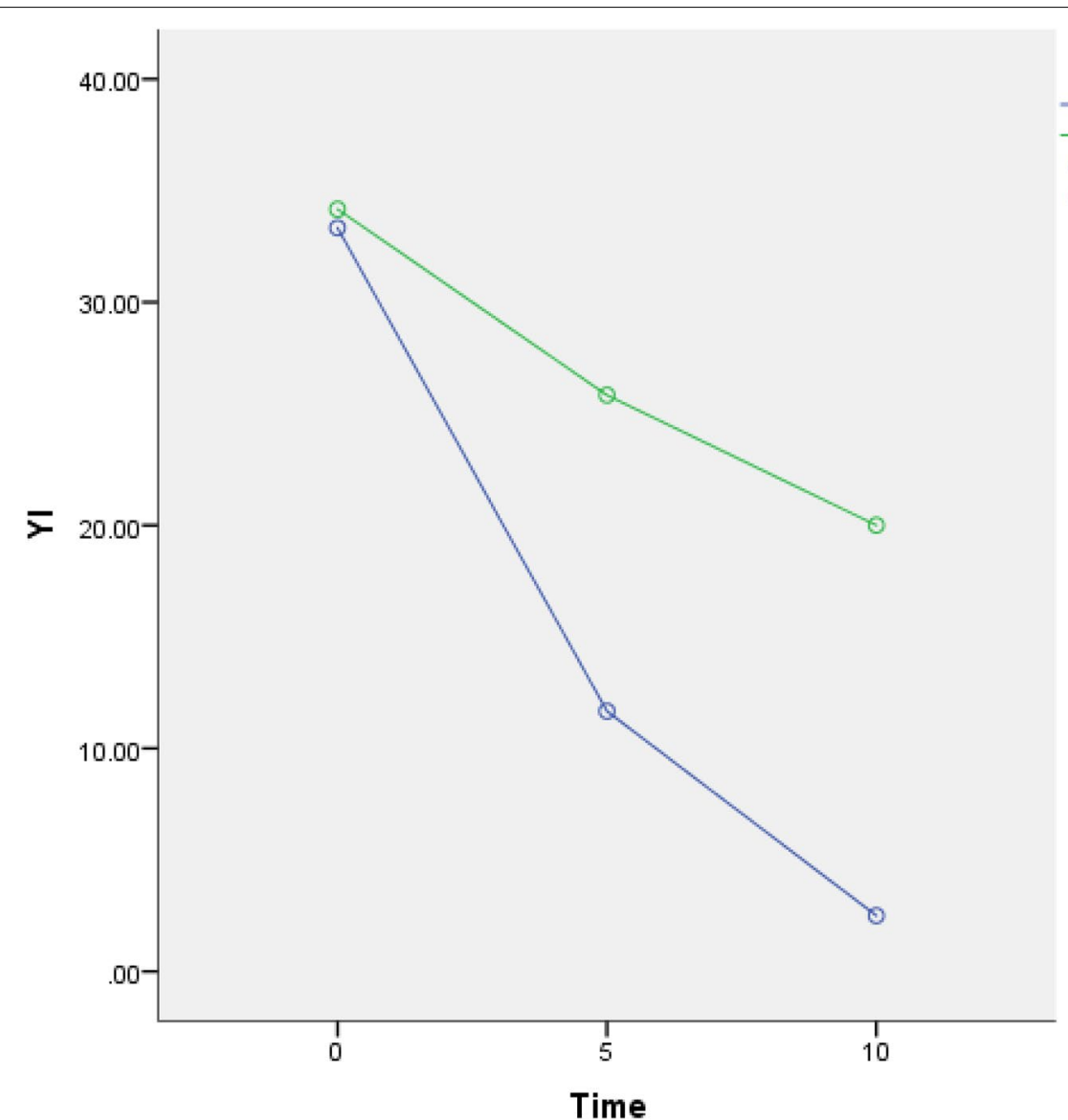

group

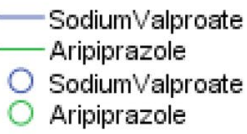

Aripiprazole

Fig. 2 The mean YGTSS impairment scale scores from baseline to endpoint 


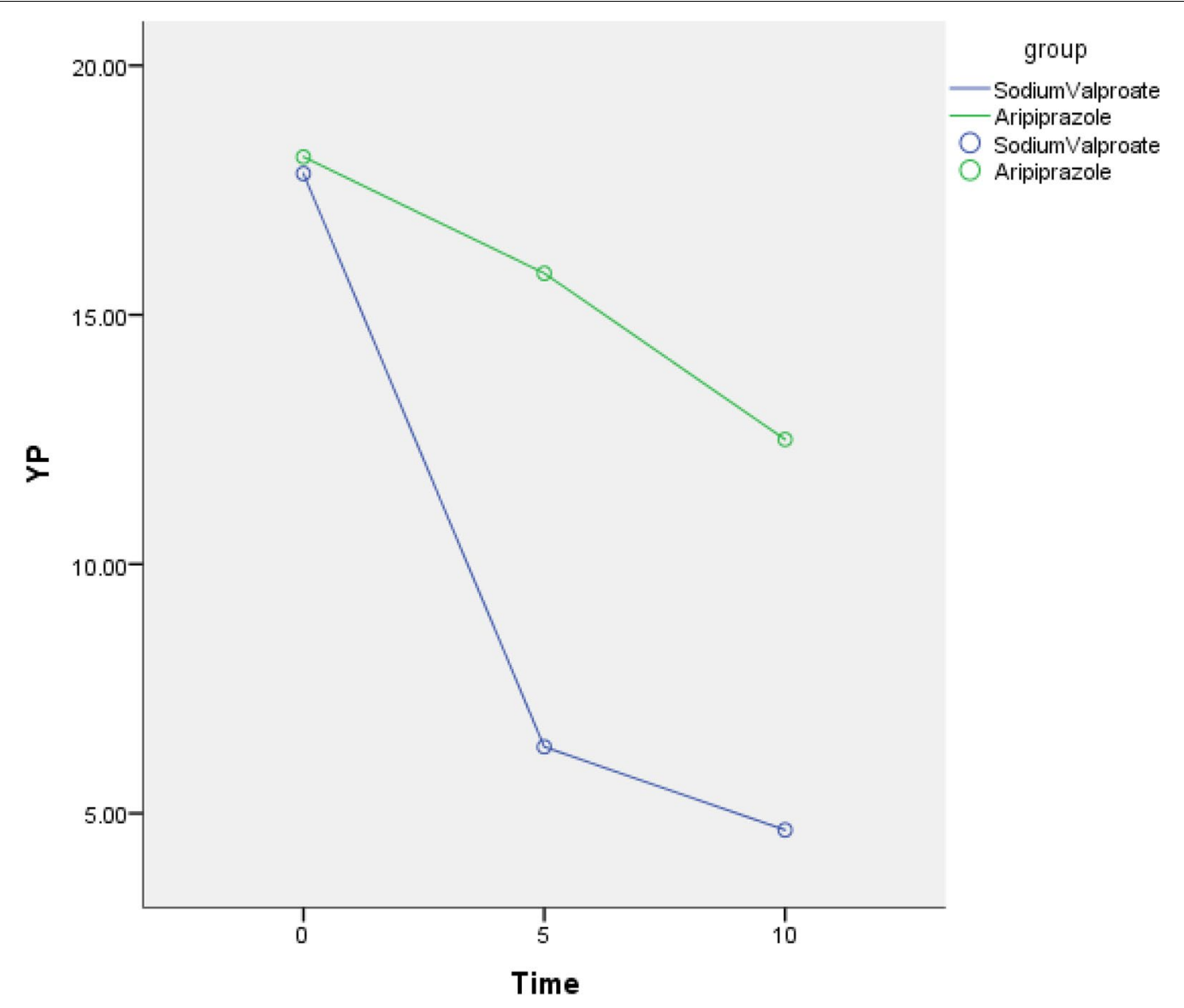

Fig. 3 The mean YGTSS total phonic scores from baseline to endpoint

\section{Discussion}

Patients having continuous phonic tics or motor tics almost all the day had severe TS, which seriously affects the daily life and mental health of patients and the impairment scale scores is extremely high. The total tic scores was above 35 and the impairment scale scores was above 30 in this experiment, indicating that the child was in a serious state of persistence at the time of treatment. The tics had a serious impact on the daily life and psychology of the children and their family members, so it is necessary to find a way to reduce the tic symptoms quickly, effectively and safely. Oral drug aripiprazole has a unique mechanism of action which needs a period for 4-8 weeks or even more longer time in controlling tics. A 10 -week multicenter, double-blind, randomized, placebocontrolled trial on 61 children and adolescents with the diagnosis of Tourette's disorder showed that aripiprazole in comparison to placebo was effective and relatively safe in the short-term treatment [23]. Another study indicates that oral aripiprazole is a safe and effective treatment for tics in children and adolescents with Tourette's disorder in 8 weeks [15]. Not only the complexity of tic disorders, but also the effectiveness and adverse effects of the medications are major challenges for us so we chose to start at a dose of $(2.5 \mathrm{mg} /$ day $<50 \mathrm{~kg}, 5 \mathrm{mg} /$ day $\geq 50 \mathrm{~kg})$ before bedtime; patients had no bad reaction after oral administration. On the 5th day, the patient still had obvious tic symptoms, and the average dose of $2.71 \mathrm{mg} /$ day was significantly lower than the average dose reported in the literature, so we adjusted to $(5 \mathrm{mg} /$ day $<50 \mathrm{~kg}$, $7.5 \mathrm{mg} /$ day $\geq 50 \mathrm{~kg}$ ). The average dose after 5 days was $5.2 \mathrm{mg} /$ day, which was lower than the average dose of previous children and adolescents, but the patients had some discomfort including lethargy (4 cases, 33.3\%) and xerostomia ( 2 cases, $16.67 \%$ ), decreased appetite ( 1 case, $8.3 \%$ ), decreased sleep (1 case, $8.3 \%$ ), and tremor (1 case, 8.3\%) [Table 4]. The adverse effects mainly occurred after the addition of treatment and the incidence of adverse effects is lower than the previous literature, which does not rule out that our observation time is short or the therapeutic dose is lower than normal. Sodium valproate (VPA) controls twitching by modulating the central 


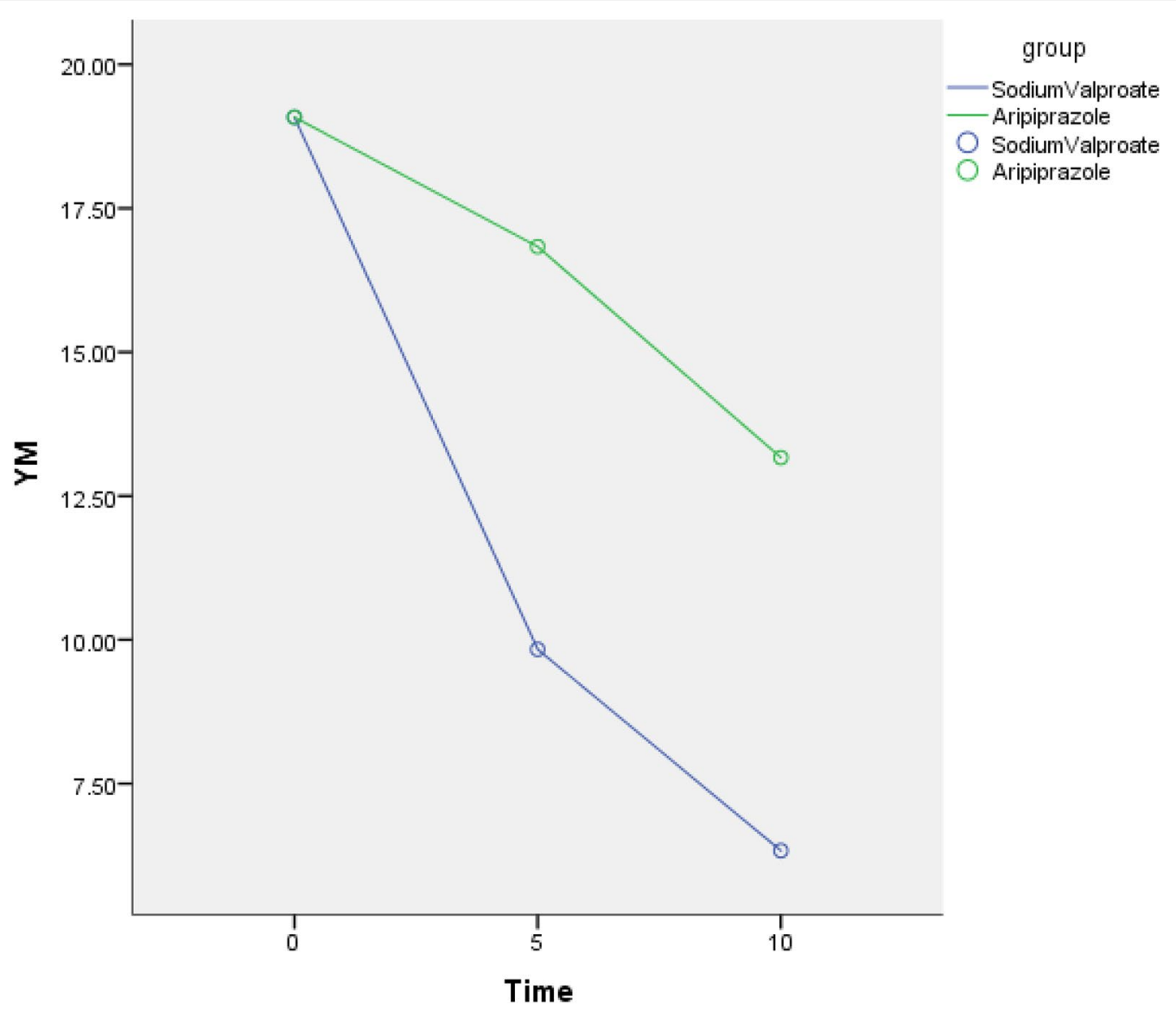

Fig. 4 The mean YGTSS motor Tic scores from baseline to endpoint

GABA system and upregulating EAAT1 mRNA and protein levels. Intravenous valproic acid does not require organic solvent to dissolve, can be injected at physiological $\mathrm{pH}$, minimizes the risk of reaction at the injection site, the incidence of adverse events is low, and the effect is stable. In the experiment, we chose the dose $30 \mathrm{mg} / \mathrm{kg} /$ day, once every $12 \mathrm{~h}$. Adverse reactions in the experiment mainly occur in the early stage of treatment and with the treatment going on, most adverse reactions disappear and does not affect normal life at all (Fig. 2).

Current results of this randomized, open-label, control clinical trial suggest that although the two groups are all effective in the reduction of tics in children and adolescents with TS, the sodium valproate group became more lower than the aripiprazole group on the day 5 , and the patient's impairment scores was also significantly lower than in the aripiprazole group. Although the family were happy with the tics scores reduction, there were still concerns about whether the condition would repeat again. The average age of the patients we selected was 6-16 years, with an average of $9-10$ years. Parents lead the children to visit many medical institutions in Beijing and Shanghai, and repeatedly carry out various examinations. The cost is huge. Some parents refuse to take regular treatment, choose to continue observation and cause the patient's condition to increase year by year. Parents are under tremendous economic and psychological pressure during the process. Due to the special pathogenesis of TS, the anxiety of parents may affect the treatment of children, and some even seriously affect the patient's condition. The family are very concerned about the speed of treatment and they need a quickly way to control tics. Some patients have self-injury behaviors due to exercise tics, the body and the psychology were all under great pressure who were also concerned about if there is a way in controlling tics quickly and safely in a short time (Fig. 3).

Our results showed that the CGI-I score of the sodium valproate group was significantly better than the aripiprazole group on the 5th day. The difference between the two groups was statistically significant $(Z=-2.705$, $p=0.008)$. It showed that with the tics scores decreased, the patients improved their self-evaluation or psychological improvement. The sodium valproate group was 
Table 4 The rate of adverse effects by the groups

\begin{tabular}{lll}
\hline Adverse events & $\begin{array}{l}\text { Sodium valproate } \\
\boldsymbol{N = 1 2} \\
(\boldsymbol{N}, \boldsymbol{\%})\end{array}$ & $\begin{array}{l}\text { Aripiprazole } \\
\mathbf{N = 1 2} \\
(\boldsymbol{N}, \%)\end{array}$ \\
\hline Drowsiness & $4,33.3 \%$ & 0 \\
Nausea & $4,33.3 \%$ & 0 \\
Xerostomia & 0 & $2,16.7 \%$ \\
Decreased sleep & 0 & $1,8.3 \%$ \\
Decreased appetite & 0 & $1,8.3 \%$ \\
Hypersomnia & 0 & $4,33.3 \%$ \\
Sensitive & $1,8.3 \%$ & 0 \\
Tremor & 0 & $1,8.3 \%$ \\
\hline
\end{tabular}

better than the aripiprazole group. On the 10th day, the CGI-I score of the sodium valproate group was significantly better than the aripiprazole group. The difference between the two groups was statistically significant $(Z=-3.104, p=0.004)$. Although aripiprazole is widely used in the treatment of tic disorder, and parents are still worried about antipsychotic drug adverse effects. There was no significant difference between the CGI scores in 5 days and 10 days $(p>0.05)$ in sodium valproate group which indicates that the patient's self-evaluation has not changed significantly with the progress of the treatment over time, but the TESS score between 5 days and 10 days has statistically significant difference $(p<0.05)$ in the sodium valproate group. The patient indicated that the symptoms are obviously improved after 5 days of treatment, but that the improvement was not as obvious as before after 10 days of treatment and the clinical improvement did not reach the expectations of the family. Increasing the days of treatment did not significantly improve the patient's impairment score while the side effects increased (Table 4), so we recommend the treatment of sodium valproate injection for 5-7 days (Fig. 4).

Because the patients selected in this study are in a relatively serious state of tic disorder, the incidence of this condition is low in the clinic. Although our department is the main medical institution for treating tic disorder in the eastern part of Heilongjiang Province, its representativeness is still limited so we hope to cooperate with more hospitals to expand the sample size in the future (Table 4).

\section{Conclusions}

The study indicates that the patients treated with sodium valproate injection have a faster onset time than the patients treated with oral aripiprazole in controlling tics. Because of the limited number of patients in our studies, we hope to cooperate with more hospitals in China to expand the sample size in the future.

\section{Abbreviations}

YGTSS: Yale Global Tic Severity Scale; EEG: electroencephalograph; MRI: magnetic resonance imaging; ECG: electrocardiograph; OD: once daily; GABA: gamma aminobutyric acid; NE: norepinephrinergic; DA: dopaminergic.

\section{Acknowledgements}

Not applicable.

\section{Authors' contributions \\ DT and XL completed the majority of the writing and data collecting. SM was involved in clinical investigations. TZ and $\mathrm{JL}$ were involved in the literature review and corrections. All authors read and approved the final manuscript.}

\section{Funding}

Not applicable.

\section{Availability of data and materials}

All data generated or analyzed during this study are included in this published article.

\section{Ethics approval and consent to participate}

This study protocol was approved by the Institutional Review Board of Jiamusi center Hospital.

\section{Consent for publication}

Not applicable.

\section{Competing interests}

The authors declare that they have no competing interests.

\begin{abstract}
Author details
${ }^{1}$ Jiamusi University, Jiamusi 154002, Heilongjiang, China. ${ }^{2}$ College of Rehab Medicine, Jiamusi University, Jiamusi, China. ${ }^{3}$ Rehab Center for Child CP,

Jiamusi, Heilongjiang, China. ${ }^{4}$ Institute of Pediatric Neurological Disorders, Jiamusi University, Jiamusi, China. ${ }^{5}$ Jiamusi Central Hospital, Jiamusi, China.
\end{abstract}

Received: 29 December 2018 Accepted: 2 September 2019

Published online: 10 October 2019

\section{References}

1. Robertson MM, Eapen V, Cavanna AE. The international prevalence, epidemiology, and clinical phenomenology of Tourette syndrome: a cross-cultural perspective. J Psychosom Res. 2009;67(6):475-83.

2. Qi Y, et al. Progress in genetic studies of Tourette's Syndrome. Brain Sci. 2017;7(10):134

3. Felling RJ, Singer HS. Neurobiology of Tourette syndrome: current status and need for further investigation. J Neurosci. 2011;31(35):12387-95.

4. Sun $\mathrm{N}$, et al. Functional evaluations of genes disrupted in patients with Tourette's disorder. Front Psychiatry. 2016;7:11.

5. Ledonne A, Mercuri NB. Current concepts on the physiopathological relevance of dopaminergic receptors. Front Cell Neurosci. 2017;11:27.

6. Meunier CN, Chameau P, Fossier PM. Modulation of synaptic plasticity in the cortex needs to understand all the players. Front Synaptic Neurosci. 2017;9:2.

7. Hu W, Chen Z. The roles of histamine and its receptor ligands in central nervous system disorders: an update. Pharmacol Ther. 2017;175:116-32.

8. Unal D, Akdemir D. Neurobiology of Tourette Syndrome. Turk Psikiyatri Derg. 2016;27(4):275-85.

9. Parkin GM, et al. Glutamate transporters, EAAT1 and EAAT2, are potentially important in the pathophysiology and treatment of schizophrenia and affective disorders. World J Psychiatry. 2018;8(2):51-63.

10. Aida T, et al. Astroglial glutamate transporter deficiency increases synaptic excitability and leads to pathological repetitive behaviors in mice. Neuropsychopharmacology. 2015;40(7):1569-79. 
11. McGuire JF. Behavior THerapy for youth with Tourette disorder. J Clin Psychol. 2016;72(11):1191-9.

12. Roessner $V$, et al. European clinical guidelines for Tourette syndrome and other tic disorders. Part II: pharmacological treatment. Eur Child Adolesc Psychiatry. 2011;20(4):173-96.

13. Simpson DM, et al. Assessment: botulinum neurotoxin for the treatment of movement disorders (an evidence-based review): report of the Therapeutics and Technology Assessment Subcommittee of the American Academy of Neurology. Neurology. 2008;70(19):1699-706.

14. Andrade P, Visser-Vandewalle V. DBS in Tourette syndrome: where are we standing now? J Neural Transm. 2016;123(7):791-6.

15. Sallee F, et al. Randomized, double-blind, placebo-controlled trial demonstrates the efficacy and safety of oral aripiprazole for the treatment of Tourette's disorder in children and adolescents. J Child Adolesc Psychopharmacol. 2017;27(9):771-81.

16. Stefanoff P, Wolanczyk T. Validity and reliability of Polish adaptation of Yale Global Tic Severity Scale (YGTSS) in a study of Warsaw school children aged 12-15. Przegl Epidemiol. 2005;59(3):753-62.

17. Wang $L J$, et al. The effectiveness of aripiprazole for tics, social adjustment, and parental stress in children and adolescents with Tourette's disorder. J Child Adolesc Psychopharmacol. 2016;26(5):442-8.

18. Wang $S$, et al. Effects of Chinese herbal medicine Ningdong granule on regulating dopamine (DA)/serotonin (5-TH) and gamma-amino butyric acid (GABA) in patients with Tourette syndrome. Biosci Trends. 2012;6(4):212-8.

19. Zhu Y, et al. Comorbid behavioural problems in Tourette's syndrome are positively correlated with the severity of tic symptoms. Aust N Z J Psychiatry. 2006;40(1):67-73.

20. Zheng P, et al. Involvement of tryptophan hydroxylase 2 gene polymorphisms in susceptibility to tic disorder in Chinese Han population. Behav Brain Funct. 2013;9:6.

21. Conners CK, Barkley RA. Rating scales and checklists for child psychopharmacology. Psychopharmacol Bull. 1985;21(4):809-43.

22. Al-Dhaher $Z$, et al. Activating and tranquilizing effects of first-time treatment with aripiprazole, olanzapine, quetiapine, and risperidone in youth. J Child Adolesc Psychopharmacol. 2016;26(5):458-70.

23. Yoo HK, et al. A multicenter, randomized, double-blind, placebo-controlled study of aripiprazole in children and adolescents with Tourette's disorder. J Clin Psychiatry. 2013;74(8):e772-e78080.

\section{Publisher's Note}

Springer Nature remains neutral with regard to jurisdictional claims in published maps and institutional affiliations.
Ready to submit your research? Choose BMC and benefit from:

- fast, convenient online submission

- thorough peer review by experienced researchers in your field

- rapid publication on acceptance

- support for research data, including large and complex data types

- gold Open Access which fosters wider collaboration and increased citations

- maximum visibility for your research: over $100 \mathrm{M}$ website views per year

At BMC, research is always in progress.

Learn more biomedcentral.com/submissions 